\title{
ADENSAMENTO, DESBASTE E ANÁlise ECONÔMICA NA PRODUÇÃo DO MARACUJAZEIRO-AMARELO ${ }^{1}$
}

\author{
SEBASTIÃO ELVIRO DE ARAÚJO NETO², JOSÉ DARLAN RAMOS², VALTER CARVALHO DE ANDRADE JÚNIOR ${ }^{3}$, \\ JOSÉ CARLOS MORAES RUFINI ${ }^{4}$, VANDER MENDONÇA ${ }^{5}$, TADÁRIO KAMEL DE OLIVEIRA ${ }^{6}$
}

\begin{abstract}
RESUMO - O objetivo deste trabalho foi avaliar o efeito de diferentes densidades de plantas sobre as características de produção, qualidade de fruto e sobre a rentabilidade econômica do maracujazeiro-amarelo. O experimento foi instalado no município de São Tiago, Minas Gerais. Os tratamentos constituíram-se de diferentes densidades de plantas na linha de plantio: T1=1,0 m (3.330 plantas/ha); T2=2,0 m (1.660 plantas/ha); T3=3,0 m $(1.110$ plantas/ha); T4=4,0 m (830 plantas/ha); T5=1,0 m (3.330/1.660 plantas/ha); T6=1,5 m (2.220/1.110 plantas/ha), e T7=2,0 m (1.660/830 plantas/ha). Nos tratamentos T5, T6 e T7, foi feito desbaste de plantas alternadas logo após o término da colheita da primeira safra. A maior produtividade foi estimada em 11,9 $\mathrm{t} \mathrm{ha}^{-1}$ na densidade de 1.841 plantas/ha na primeira safra, média de 10,9 $\mathrm{t} \mathrm{ha}^{-1}$ na segunda safra e 5,46 tha ${ }^{-1}$ na terceira safra. A produtividade total foi menor para o sistema menos adensado ( 830 plantas/ha), com 25,6 t ha $\mathrm{a}^{-1}$ e média de 27,96 tha $\mathrm{t}^{-1}$ para os demais tratamentos. O peso médio de fruto não foi alterado com o adensamento, com exceção da segunda safra, que produziu frutos maiores no plantio adensado. $\mathrm{O}$ adensamento não alterou a qualidade do fruto. A média das três safras para as características de qualidade foi: peso médio de fruto (126 g), rendimento de suco (34,9\%), sólidos solúveis totais $(14,6 \%)$ e acidez total titulável (4,9\%). A máxima eficiência econômica foi alcançada na densidade de 1.110 plantas/ha.
\end{abstract}

Termos para indexação: Passiflora edulis f. flavicarpa Deg.; produtividade, qualidade.

\section{DENSITY, ROUGH-HEWING AND ECONOMICAL ANALYZE IN CROPS OF YELLOW PASSION FRUIT PLANTS}

ABSTRACT - The purpose of this work was to evaluate different planting densities of plants over yield characteristics, fruit quality and economical performance of yellow passion fruit. The experiment was carried out in São Tiago county, Minas Gerais, Brazil. The treatments used different plants density in the planting row: $\mathrm{T} 1=1.0 \mathrm{~m}(3,330 \mathrm{plants} / \mathrm{ha}) ; \mathrm{T} 2=2.0 \mathrm{~m}(1,660$ plants $/ \mathrm{ha}) ; \mathrm{T} 3=3.0 \mathrm{~m}(1,110 \mathrm{plants} / \mathrm{ha}) ; \mathrm{T} 4=4.0 \mathrm{~m}(830 \mathrm{plants} / \mathrm{ha}) ; \mathrm{T} 5=1.0$ $\mathrm{m}(3,330 / 1,660 \mathrm{plants} / \mathrm{ha}) \mathrm{T} 6=1.5 \mathrm{~m}(2,220 / 1,110 \mathrm{plants} / \mathrm{ha})$ e T7 $=2.0 \mathrm{~m}(1,660 / 830$ plants/ha). The treatments T5, T6 and T7, were hewed alternately right after the first crop's harvest. The highest yield was $11.9 \mathrm{t} \mathrm{ha}^{-1}$ in the planting density of 1,841 plants/ha in its first crop, it was about $10.9 \mathrm{t}$ ha ${ }^{-1}$ average in its second crop and $5.46 \mathrm{tha}^{-1}$ in its third crop. The total yield was less in the lower density planting (830 plants/ha), $25.6 \mathrm{t} \mathrm{ha-1}$, and an average of $27.96 \mathrm{t} \mathrm{ha}^{-1}$ for the others treatments. The average fruit weight did not change with planting density, except in the second crop that gave larger fruit in the denser planting. Planting density did not alter fruit quality. The average of the three crops for quality characteristics were: fruit average weight (126 g); juice yield (34.9\%); total solid soluble (14.6\%) and total acidity titratable (4.9\%). The most economical efficiency reached was in planting density of 1,110 plants/ha.

Index terms: Passiflora edulis Sims. f. flavicarpa Deg.; yield, quality.

\section{INTRODUÇÃO}

A importância da cultura do maracujazeiro-amarelo (Passiflora edulis Sims f. flavicarpa Degener) para o Brasil está no volume produzido e na geração de emprego no campo.

Na safra de 2002, a produção nacional concentrou-se nos seguintes estados produtores: Bahia, Espírito Santo e São Paulo que, juntos, foram responsáveis por $51 \%$ da produção e por $42 \%$ da área colhida. O Estado de Minas Gerais participou com 7,2\% da produção brasileira. Nesta safra de 2002, a maior produtividade foi atingida no Estado do Espírito Santo, com média de 27,4 t ha-1 , enquanto a média nacional foi de 13,47 tha $\mathrm{t}^{-1}$ (Brasil, 2005).

Nos últimos anos, tem-se buscado maior aproveitamento de áreas exploradas com fruteiras, notadamente com diminuição do espaçamento, visando a colocar maior número de plantas em menor área, maximizando a produtividade.

No Brasil, diversos trabalhos com maracujazeiro revelaram resultados significativos de aumento de produtividade para o adensamento onde em densidade de 5.000 plantas/ha, correspondendo ao espaçamento de 2,0 m x 1,0 m, (Pace \& Araújo, 1981), obtiveram produtividade de 33,1 $\mathrm{t} \mathrm{ha}^{-1}$ na primeira safra. Andrade et al. (1994) constataram que o espaçamento $3,0 \mathrm{~m}$ x 1,5 m produziu, na primeira safra $14,5 \mathrm{tha}^{-1}$, que representou $219 \%$ a mais que o maior espaçamento $(3,0 \mathrm{~m}$ x 6,0 m). São José (1998) recomenda plantio com espaçamento de 3,5 m x
1,75 m conduzindo um potencial produtivo de $20 \mathrm{tha}^{-1}$. Contudo, alguns trabalhos não revelaram efeito significativo, para diferentes densidades, como os de Cereda \& Vasconcelos (1991), com produtividade média de $26,4 \mathrm{t} \mathrm{ha}^{-1}$ e densidades variando de 833 a 3.333 plantas/ha e Manica et al. (1989), com produtividade média de $12,8 \mathrm{tha}^{-1} \mathrm{em}$ densidade variando de 695 a 2.000 plantas/ha. Além disso, a maior produtividade obtida com o adensamento pode não proporcionar maior retorno econômico (Kits et al., 1996).

A densidade de plantio em maracujazeiro praticamente não influencia na qualidade do fruto (Pace \& Araújo, 1981; Cereda \& Vasconcelos, 1991; Andrade et al., 1994). A qualidade do fruto pode ser influenciada pelo número de frutos por planta. Silva \& Oliveira (2001) afirmam que o maior número de frutos por planta em espaldeira tipo "caramanchão" ou "latada" produz frutos menores que em espaldeira vertical com frutos grandes, mas em menor número por área.

Torna-se evidente a dificuldade em decidir pelo espaçamento que proporcione boa produtividade para o maracujazeiro, principalmente por não ter sido realizado nenhum trabalho avaliando a produtividade e a eficiência econômica em sistema adensado no sul de Minas Gerais, região que possui restrições climáticas para o maracujazeiro, principalmente durante o inverno, alterando o comportamento biológico da planta.

O adensamento no plantio do maracujazeiro poderá propiciar maior produtividade na primeira safra (safrinha), podendo o desbaste de

\footnotetext{
(Trabalho 048/2005). Recebido: 16/03/2005. Aceito para publicação: 08/12/2005.

${ }^{2}$ Eng $^{\circ}$. Agr ${ }^{\circ}$. D.Sc. Fitotecnia. Professor de Fruticultura da Universidade Federal do Acre, Rio Branco-Acre. CEP 69.915-900 fone: (068) 3901-2524; e-mail:selviro@ufac.br (Trabalho com concessão de bolsa da CAPES para Doutoramento).

${ }^{2}$ Eng $^{\circ}$. Agr ${ }^{\circ}$. D.Sc. Fitotecnia. Prof ${ }^{\circ}$. das Faculdades Federais Integradas de Diamantina-MG. valter@fafeid.br.

${ }^{3}$ Eng $^{\circ}$. Agr ${ }^{\circ}$. D. Sc. Fitotecnia. Prof ${ }^{\circ}$. Fruticultura da Universidade Federal de Lavras. darlan@ufla.br.

${ }^{4}$ Eng $^{\mathrm{o}}$. Agr ${ }^{\circ}$. D. Sc. Fitotecnia. Prof . da UNIVALE, Governador Valadares-MG. e-mail: jcrufini@mgconecta.com.br.

${ }^{5}$ Eng $^{\circ}$. Agr ${ }^{\circ}$. D.Sc. Fitotecnia. Prof ${ }^{\circ}$. da Universidade Estadual do Mato Grosso do Sul. vanderm@uems.br.

${ }^{6}$ Eng $^{\circ}$. Agr ${ }^{\circ}$. D.Sc. Engenharia Florestal. Pesquisador da Embrapa-Acre. tadario@cpafac.embrapa.br.
} 
plantas após a primeira safra permitir menor competição e maior vigor vegetativo e produtividade nas plantas remanescentes. É importante também avaliar o retorno econômico durante todo o ciclo do cultivo, gerando assim maior credibilidade em trabalhos dessa natureza.

Portanto, o objetivo deste trabalho foi avaliar o efeito de diferentes densidades de plantas sobre as características de produção, qualidade de fruto e a rentabilidade econômica do maracujazeiro-amarelo.

\section{MATERIAL E MÉTODOS}

O experimento foi realizado em pomar comercial da Fazenda Sant'Ana, município de São Tiago-MG (44 $36^{\prime}$ oeste e $20^{\circ} 54^{\prime}$ sul). O delineamento experimental utilizado foi o de blocos casualizados com cinco tratamentos e quatro repetições. Os tratamentos constituíram-se de diferentes densidades e desbaste de plantas na linha de plantio: T1= 1,0 m (3.330 plantas/ha); T2=2,0 m (1.660 plantas/ha); T3=3,0 $\mathrm{m}(1.110$ plantas/ha); T4=4,0 $\mathrm{m}$ ( 830 plantas/ha); T5=1,0 $\mathrm{m}$ (3.330 plantas/há, com desbaste de plantas alternadas a partir da segunda safra); T6 $=1,5 \mathrm{~m}$ (2.220 plantas/há, com desbaste de planta), e T7=2,0 m (1.660 plantas/ ha, com desbaste de plantas).

O plantio foi realizado em outubro de 2001, e as colheitas, durante o primeiro semestre de 2002, 2003 e 2004, pois, no segundo semestre, ocorre a entressafra na região. As adubações de formação e produção, a condução e os demais tratos culturais foram realizados de acordo com Ruggiero et al. (1996) e Quaggio e Piza Júnior (1998). Não foi utilizada a polinização artificial.

Foram contados e pesados duas vezes por semana, todos os frutos de cada parcela, que serviu para estimar a produtividade $\left(\mathrm{t} \mathrm{ha}^{-1}\right), \mathrm{o}$ número de frutos por planta e por área e o peso médio dos frutos $(\mathrm{g})$.

Próximo ao final de cada safra, foram coletados 5 frutos de cada parcela para avaliação de suas características: rendimento de suco (\%); sólidos solúveis totais - SST (\%) e acidez total titulável - ATT (\%).

O teor de sólidos solúveis totais foi determinado diretamente do suco, com refratômetro digital de compensação automática de temperatura. Os valores de sólidos solúveis totais foram expressos em porcentagem (AOAC, 1990).

A acidez total titulável foi analisada pela titulação de um extrato ( $1 \mathrm{ml}$ de suco/50ml água destilada), com hidróxido de sódio ( $\mathrm{NaOH}, 0,1$ N), expresso em porcentagem de ácido cítrico (AOAC, 1990).

O suco foi obtido, batendo-se a polpa no liquidificador de forma intermitente, sem danificar as sementes, passando em seguida por peneira de malha fina. O rendimento de suco foi determinado pelo cociente entre o peso do suco e do fruto, multiplicado por 100.

Para o procedimento de estimativa do custo de produção, conceituado como a soma de todos os valores (insumos) e operações (serviços) utilizados no processo produtivo da atividade, incluindo os respectivos custos alternativos ou de oportunidade, dividiram-se os custos em fixos e variáveis. Para o cálculo dos custos fixos, foi desconsiderada a depreciação de máquinas e equipamentos, por utilizar o preço de alocação, prática adotada na região, por se tratar de produtores com, no máximo, um hectare com maracujazeiro. Para efeito da análise do custo alternativo dos recursos alocados na produção, considerou-se a taxa de juros de $12 \%$ a. a.

$O$ custo de cada recurso fixo foi calculado somando-se o custo alternativo do fator produtivo. Foram considerados como custo fixo, o arrendamento da terra, imposto territorial rural (ITR) e 50\% do valor do arame utilizado na espaldeira (amortização), independentemente da quantidade de mudas plantadas por unidade de área (espaçamento), enquanto os fatores variáveis estão associados diretamente às quantidades de mudas.

Os custos variáveis foram calculados pelo desembolso realizado para a aquisição de produtos e serviços somados ao custo alternativo. Os recursos variáveis e a forma de operacionalização utilizada foram:

Mão-de-obra: referente às operações de plantio e condução da planta (plantio, tutoramento, poda e desbaste de plantas), empregadas especialmente para cada unidade de espaçamento, além das outras operações utilizadas, independentemente do espaçamento adotado.

Insumos: corresponde ao gasto com aquisição de fertilizantes químicos, matéria orgânica, alocação de máquinas e equipamentos, defensivos e micronutrientes.

Os preços de insumos e mão-de-obra foram levantados na região da localização do experimento.

A análise econômica compreendeu: Análise econômica simplificada e Receita Líquida, baseado em Reis (2002).

Para a análise estatística dos dados da safrinha, foram utilizados apenas os tratamentos T1, T2, T3, T4 e T6, pois os tratamentos T5 e T7 só diferem de T1 e T2 a partir da segunda safra. Cada parcela constituise de $36 \mathrm{~m}^{2}$, com $12 \mathrm{~m}$ de comprimento por 3,0 m de largura, compreendendo o espaçamento entre linhas. Os dados foram analisados por análise de variância seguido do teste de Tukey, a 5\% de probabilidade. Apenas para os dados da safrinha foi realizada análise de regressão.

\section{RESULTADOS E DISCUSSÃO}

Houve diferenças estatísticas da produtividade entre os tratamentos na primeira safra e produtividade total (Tabela 1). Analisando apenas a safrinha, observa-se que a máxima produtividade foi de 11,9 t/ ha na densidade de 1.841 plantas/ha, que corresponde ao espaçamento de 3,0 $\mathrm{m} \times 1,8 \mathrm{~m}$ (Figura 1). Outros trabalhos também revelaram aumento da produtividade na primeira safra em plantios adensados (Pace \& Araújo, 1981; Ritzinger et al., 1987; Andrade et al., 1994; Manica et al., 1994b; São José, 1998).

Ritzinger et al. (1987) afirmam que o aumento da densidade de plantio eleva a produção numa correlação direta com o acréscimo de frutos por área, apesar de o número de frutos por planta ser significativamente menor. E a menor densidade na linha de plantio diminui a sobreposição de ramos até um ponto em que não mais interfere no

TABELA 1 - Produtividade, número de frutos por planta e número de frutos por área do maracujazeiro-amarelo em diferentes densidades de plantio com eliminação de plantas na segunda e terceira safras, em São Tiago-MG.

\begin{tabular}{|c|c|c|c|c|c|c|c|c|c|c|c|c|c|c|}
\hline \multirow{2}{*}{$\begin{array}{c}\text { Tratamentos } \\
\text { Espaçamento (m) }\end{array}$} & \multicolumn{2}{|c|}{$\begin{array}{r}\text { Densidade } \\
\text { (plantas/ha) }\end{array}$} & \multicolumn{4}{|c|}{ Produtividade $(\mathrm{t} / \mathrm{ha})$} & \multicolumn{4}{|c|}{ Número de frutos por planta } & \multicolumn{4}{|c|}{ Número de frutos por área } \\
\hline & $1^{\circ}$ ano & $\begin{array}{l}2^{\circ} \mathrm{e} 3^{\circ} \\
\text { anos }\end{array}$ & $1^{\circ}$ ano & $2^{\circ}$ ano & $3^{\circ}$ ano & Média & $1^{\circ}$ ano & $2^{\circ}$ ano & $3^{\circ}$ ano & Média & $1^{\circ}$ ano & $2^{\circ}$ ano & $3^{\circ}$ ano & Total \\
\hline $\mathrm{T} 1=3,0 \times 1,0$ & 3330 & 3330 & $11,72 \mathrm{a}^{\mathrm{I}}$ & $9,71 \mathrm{a}$ & $5,06 a$ & $26,49 \mathrm{ab}$ & $35,3 d$ & $23,0 \mathrm{c}$ & $8,5 \mathrm{~d} x \mathrm{x}$ & $22,5 \mathrm{~d}$ & $49 \mathrm{ab}$ & $\overline{7.590 \mathrm{a}}$ & 29 & $2.444 b$ \\
\hline $\mathrm{T} 2=3,0 \times 2,0$ & 1660 & 1660 & $11,24 a b$ & $10,47 \mathrm{a}$ & $4,48 \mathrm{a}$ & $26,19 a b$ & $67,0 \mathrm{c}$ & $50,3 b$ & $16,0 \mathrm{cdx}$ & $44,3 \mathrm{c}$ & $111.220 \mathrm{ab}$ & $83.498 \mathrm{a}$ & 26 & $221.278 b$ \\
\hline $\mathrm{T} 3=3,0 \times 3,0$ & 1111 & 1111 & $11,74 \mathrm{a}$ & $11,93 \mathrm{a}$ & $5,66 \mathrm{a}$ & $29,34 a b$ & $97,5 b$ & $85,5 \mathrm{a}$ & $32,5 a b c$ & $71,8 b$ & $108.225 b c$ & $94.905 \mathrm{a}$ & $35.075 \mathrm{a}$ & $239.205 \mathrm{ab}$ \\
\hline $\mathrm{T} 4=3,0 \times 4,0$ & 830 & 830 & $9,28 b$ & $9,95 \mathrm{a}$ & $6,38 \mathrm{a}$ & $25,62 b$ & $110,8 \mathrm{a}$ & $103,5 \mathrm{a}$ & $51,3 \mathrm{axx}$ & $88,5 \mathrm{a}$ & $91.964 \mathrm{c}$ & $85.905 \mathrm{a}$ & $42.579 a$ & $220.448 b$ \\
\hline $\mathrm{T} 5=3,0 \times 1,0 \mathrm{c} / \mathrm{des}$ & o. 3330 & 1660 & $(12,10)^{2}$ & $11,18 \mathrm{a}$ & $5,70 \mathrm{a}$ & $28,98 \mathrm{ab}$ & $(38,0)$ & $55,8 b$ & $22,8 \mathrm{bcd}$ & $38,5 \mathrm{c}$ & $(126.540)$ & $92.628 \mathrm{a}$ & $37.848 \mathrm{a}$ & $257.016 \mathrm{ab}$ \\
\hline $\mathrm{T} 6=3,0 \times 1,5 \mathrm{c} / \mathrm{des}$ & 2220 & 1111 & $11,94 \mathrm{a}$ & $12,37 \mathrm{a}$ & $6,03 \mathrm{a}$ & $30,34 \mathrm{a}$ & $57,0 \mathrm{c}$ & $90,5 \mathrm{a}$ & $37,5 \mathrm{abc}$ & $61,5 b$ & $126.540 \mathrm{a}$ & $100.455 a$ & $41.625 a$ & $268.620 \mathrm{a}$ \\
\hline $\mathrm{T} 7=3,0 \times 2,0 \mathrm{c} / \mathrm{des}$ & 1660 & 830 & $(10,85)$ & $10,70 \mathrm{a}$ & $4,89 \mathrm{a}$ & $26,45 \mathrm{ab}$ & $(63,0)$ & $103,0 \mathrm{a}$ & $40,5 \mathrm{abx}$ & $69,0 \mathrm{~b}$ & $(104.580)$ & $85.490 \mathrm{a}$ & $33.615 \mathrm{a}$ & $219.811 \mathrm{ab}$ \\
\hline \multicolumn{3}{|c|}{ Coeficiente de variação (\%) } & 9,24 & 11,85 & 28,58 & 7,03 & 7,18 & 12,99 & 33,63 & 8,09 & 7,25 & 11,71 & 30,24 & 6,90 \\
\hline
\end{tabular}

(1) Média seguidas de mesma letra na coluna não diferem entre si, pelo teste de Tukey, ao nível de 5\% de probabilidade.

${ }^{(2)}$ Médias entre parênteses não foram analisadas estatisticamente na avaliação da primeira safra. 


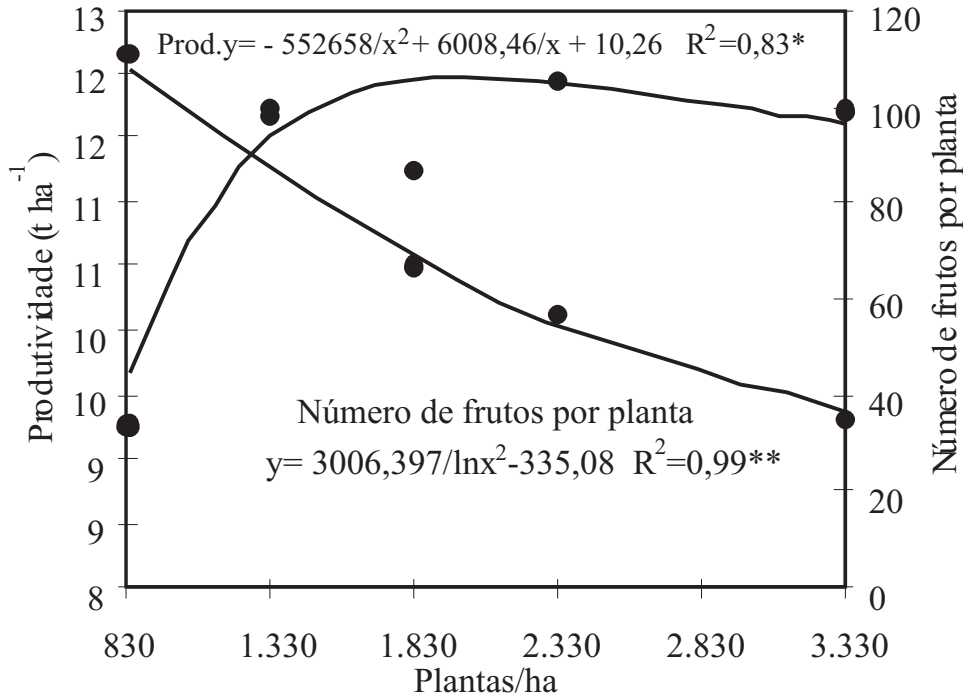

FIGURA 1 - Produtividade e número de frutos por planta na primeira safra do maracujazeiro-amarelo em diferentes densidades de plantio.

desenvolvimento e produção de frutos. Portanto, nesse ponto, pode-se esperar o máximo da capacidade produtiva permitida pela constituição genética das plantas e manejo da cultura adotado, não havendo mais ganho de produção com aumento dos espaçamentos. Os autores ainda relatam ser de 2,5 m entre linhas por 5,0 m entre plantas na linha o espaçamento que possibilita a máxima capacidade produtiva das plantas, quando se analisa individualmente a produção de cada planta, mas que para produtividade por área, o espaçamento mais produtivo foi de $2,5 \mathrm{~m}$ x $2,0 \mathrm{~m}$, com produtividade $70 \%$ maior que o maior espaçamento testado (2,5 $\mathrm{m} \times 5,75 \mathrm{~m})$, comprovando que o menor número de frutos em plantas adensadas é compensado pelo maior número de plantas por área.

Analisando-se a produtividade total $\left(\mathrm{t} \mathrm{ha}^{-1}\right)$, verifica-se que o espaçamento de $3,0 \mathrm{~m} \times 1,5 \mathrm{~m}$ com desbaste de plantas produziu apenas $18,4 \%$ mais que o espaçamento de $3,0 \mathrm{~m} \mathrm{x} \mathrm{4,0} \mathrm{m}$, por apresentarem baixa produção, na primeira e segunda safras (Tabela 1). Resultados semelhantes foram encontrados por Pace \& Araújo (1981), em que a maior produtividade, referente às duas únicas safras analisadas $(57,2 \mathrm{t}$ $\mathrm{ha}^{-1}$ ), foi obtida no espaçamento de 2,5 m x 1,0 m e por Kits et al. (1996), a produtividade de três safras $\left(51,9 \mathrm{tha}^{-1}\right)$ no espaçamento de 2,0 x 1,25 $\mathrm{m}$.

Houve diferenças estatísticas entre os efeitos dos tratamentos para a média do número de frutos por planta das três safras analisadas e separadamente em cada safra (Tabela 1).

A relação entre o número de frutos por planta e as diferentes densidades de plantio teve resposta inversa (Figura 1). Portanto, à medida que aumentou o número de plantas, diminui o número de frutos por planta. Resultados semelhantes foram encontrados por Pace \& Araújo (1981), Ritzinge et al. (1987), Cereda \& Vasconcelos (1991) e Manica et al. (1994a).

Houve diferenças estatísticas entre os efeitos dos tratamentos para a média do número de frutos por área na primeira safra e para a média da somatória das três safras (Tabela 1).

O menor número de frutos por planta pode estar relacionado com o menor número de flores e menor frutificação, causada pelo alto sombreamento das plantas adensadas (Andrade et al., 1994). Este sombreamento, causado pelo entrelaçamento dos ramos das plantas adensadas, é maior e afeta mais a produção quando varia a densidade de plantas na linha ao invés de variar o espaçamento entre linhas (Sacramento \& Pinto, 1989). Por isso, a diminuição acentuada do espaçamento proporciona uma grande ocupação da área disponível na espadeira, ocorrendo o entrelaçamento dos ramos e maior competição entre as plantas por luz e aeração, diminuindo a produção (Manica et al., 1994a). Nessa lógica, a maior produção de frutos por área, nos tratamentos com desbaste de plantas, pode estar relacionado com a diminuição da competição entre plantas.

Com relação ao efeito da densidade de plantio sobre o peso médio do fruto, houve diferenças estatísticas apenas na segunda safra (Tabela 2), apesar de o número de frutos por planta, nas três safras, ter sido menor nos espaçamentos adensados e, conseqüentemente, haver "menor competição" entre esses frutos. Mesmo assim, não foi suficiente para aumentar o peso médio dos mesmos. Cereda \& Vasconcellos (1991) afirmam que o peso médio de frutos é pouco influenciado pela maior ou menor produção por planta.

TABELA 2 - Peso médio do fruto do maracujazeiro-amarelo em diferentes densidades de plantio com eliminação de plantas na segunda e terceira safras, em São Tiago-MG.

\begin{tabular}{|c|c|c|c|c|c|c|}
\hline \multirow{2}{*}{$\begin{array}{c}\text { Tratamentos } \\
\text { Espaçamento }(\mathrm{m})\end{array}$} & \multicolumn{2}{|c|}{$\begin{array}{c}\text { Densidade } \\
\text { (plantas/ha) }\end{array}$} & \multicolumn{4}{|c|}{ Peso médio do fruto $(\mathrm{g})^{*}$} \\
\hline & $1^{\mathrm{o}}$ an & $\begin{array}{l}2^{\circ} \mathrm{e} 3^{\circ} \\
\text { ano }\end{array}$ & $1^{\circ}$ ano & $2^{\circ}$ ano & $3^{\circ}$ ano & Média \\
\hline $\mathrm{T} 1=3,0$ & 3330 & 3330 & & 12 & $175,5 \mathrm{a}$ & 135,0 \\
\hline $\mathrm{T} 2=3,0 \times 2,0$ & 1660 & 1660 & 100,9 a 1 & $a b$ & $8 \mathrm{a}$ & $124,5 \mathrm{a}$ \\
\hline $\mathrm{T} 3=3,0 \times 3,0$ & 1111 & 1111 & 108,8 a 1 & $126,4 \mathrm{ab}$ & $157,3 \mathrm{a}$ & $130,8 \mathrm{a}$ \\
\hline $\mathrm{T} 4=3,0 \times 4,0$ & 830 & 830 & 100,7 a 1 & 115,4 ba & $151,5 \mathrm{a}$ & $122,3 \mathrm{a}$ \\
\hline $\mathrm{T} 5=3,0 \times 1,0 \mathrm{c} / \mathrm{desb}$ & .3330 & 1660 & $(101,7) 1$ & $121,0 \mathrm{ab}$ & $150,4 \mathrm{a}$ & $124,3 \mathrm{a}$ \\
\hline $\mathrm{T} 6=3,0 \times 1,5 \mathrm{c} / \mathrm{desb}$ & .2220 & 1111 & 99,1 a 1 & $123,6 \mathrm{ab}$ & $149,3 \mathrm{a}$ & $124,0 \mathrm{a}$ \\
\hline $\mathrm{T} 7=3,0 \times 2,0 \mathrm{c} / \mathrm{desb}$ & .1660 & 830 & $(103,0) 1$ & $124,8 \mathrm{ab}$ & $144,7 \mathrm{a}$ & $124,3 \mathrm{a}$ \\
\hline Coeficiente de vari & $5(\%$ & & 5,22 & 4,19 & 13,01 & 4,93 \\
\hline
\end{tabular}

*Média seguidas de mesma letra na coluna não diferem entre si, pelo teste de

Tukey, ao nível de 5\% de probabilidade.

Com isso, fica claro que a produtividade do maracujazeiro é mais influenciada pelo número do que pelo peso médio dos frutos. Esses resultados corroboram os obtidos por Pace \& Araújo (1981), Ritzinger et al. (1987), Cereda \& Vasconcelos (1991), Andrade et al. (1994) e Manica et al. (1994b).

No plantio adensado, a área foliar por planta não aumenta proporcionalmente em relação ao aumento do número de plantas. Além disso, o sombreamento de ramos diminui a área foliar que serve de fonte e aumenta a área foliar que serve de dreno. Portanto, existe uma relação entre a área foliar disponível e o número de frutos de uma planta que estão diretamente relacionados com o tamanho e o peso dos frutos (Forshey \& Elfving, 1977).

Mas, neste experimento, o peso médio dos frutos da segunda safra pode ter sido influenciado pelo número de frutos por planta, pois o tratamento com menor densidade de plantio (T4) apresentou o maior número de frutos por planta bem como o menor peso médio do fruto. A diferença do peso médio dos frutos entre os tratamentos de maior e menor densidade de plantio (T4 e T1) foi de $11,7 \%$, portanto indicando ter possivelmente havido competição entre os frutos, já que, no espaçamento de 3,0 m x 4,0 m (T4), o número de frutos por planta foi maior $(450 \%)$ que nas plantas de T1. Isto torna-se evidente, também, quando a espaldeira é do tipo "caramanchão", que viabiliza maior produtividade, porém menor número de frutos, sendo mais recomendada inclusive para indústria (Silva \& Oliveira, 2001).

O rendimento de suco não foi influenciado pela densidade de plantas, em nenhuma das três safras (teste $\mathrm{F}$, a $5 \%$ de probabilidade) e variou de $34,32 \%$ a $38,50 \%$ na primeira safra, de $30,91 \%$ a $38,32 \%$ na segunda safra e de $33,42 \%$ a $36,81 \%$ (Tabela 3 ) na terceira safra. Esses valores situam-se dentro da amplitude de variação para o fruto do maracujazeiro (Gamarra Rojas \& Medina, 1995; Ruggiero et al., 1996; Lima et al., 2002).

Dos trabalhos desenvolvidos com o objetivo de avaliar o efeito do espaçamento na produção do maracujazeiro, poucos avaliaram o rendimento de suco, a exemplo de Andrade et al. (1994) que, também, não observaram influência da densidade de plantas sobre esta característica.

O teor de sólidos solúveis totais não foi influenciado pela 
TABELA 3 - Rendimento de suco, sólidos solúveis totais (SST) e acidez total titulável (ATT) do maracujá produzido em diferentes densidades de plantio com eliminação de plantas na segunda e terceira safras, em São Tiago-MG.

\begin{tabular}{lcccc}
\hline $\begin{array}{c}\text { Tratamentos } \\
\text { Espaçamento (m) }\end{array}$ & $\begin{array}{c}\text { Densidade } \\
\text { (plant./ha) }\end{array}$ & $\begin{array}{c}\text { Rend. de. } \\
1^{\circ} \text { ano } \begin{array}{c}2^{\circ} 3^{\circ} \\
\text { ano }\end{array}\end{array}$ & $\begin{array}{l}\text { SST } \\
\text { Suco (\%) }\end{array}$ & $\begin{array}{c}\text { ATT } \\
(\%)\end{array}$ \\
\hline T1=3,0x1,0 & $3330 / 3330$ & 35,76 & 14,57 & 5,09 \\
T2=3,0x2,0 & $1660 / 1660$ & 34,42 & 14,36 & 4,92 \\
T3=3,0x3,0 & $1111 / 1111$ & 36,58 & 14,78 & 4,87 \\
T4=3,0x4,0 & $830 / 830$ & 32,92 & 15,22 & 4,87 \\
T5=3,0x1,0 c/desb. 3330/1660 & 33,85 & 14,99 & 4,73 \\
T6=3,0x1,5 c/desb. 2220/1111 & 36,43 & 14,50 & 5,14 \\
T7=3,0x2,0 c/desb. 1660/830 & 34,02 & 14,06 & 4,80 \\
\hline Coeficiente de variação (\%) & 10,58 & 6,21 & 7,62 \\
\hline
\end{tabular}

densidade de plantas. A variação dos valores de SST foi de $15,90 \%$ a $17,29 \%$ na primeira safra, de $13,64 \%$ a $14,98 \%$ na segunda safra e de $11,65 \%$ a $13,78 \%$ na terceira safra (Tabela 3 ), observando-se uma pequena redução na segunda safra e uma redução significativa na terceira safra. Estes resultados estão dentro da variação para os frutos do maracujazeiro (Arjona et al., 1992; Lima et al., 2002).

Em maracujá, o teor de SST é composto principalmente por açúcares (68\%) e ácidos orgânicos (29\%), além de outros compostos. E os açúcares acumulados nos frutos são produzidos a partir do metabolismo fotossintético da planta que acumula, primeiramente, sacarose, que geralmente é convertida posteriormente em glicose e frutose (Kays, 1991).

Assim como para peso médio de frutos, não houve diferença na concentração de SST nos frutos das plantas nas diferentes densidades de plantio, pelo equilíbrio entre área foliar fotossinteticamente ativa e número de frutos, pois nas plantas em maiores espaçamentos, a possível maior atividade fotossintética pode ter sido translocada para o maior número de frutos por planta.

A acidez total titulável do fruto não foi influenciada pela densidade de plantas pelo teste $\mathrm{F}$, a $5 \%$ de probabilidade. A variação na ATT foi de $4,31 \%$ a 5,25\% na primeira safra, de $4,61 \%$ a $5,47 \%$ na segunda safra e de $4,80 \%$ a 5,47\% (Tabela 3)na terceira safra. O teor de acidez total titulável dos frutos está dentro da variação encontrada para o maracujá (Arjona et al., 1992; Lima et al., 2002; Nascimento et al., 2003).

Os ácidos orgânicos são formados primeiramente por oxidação, descarboxilação e, em alguns casos, carboxilação na cadeia respiratória do ácido tricarboxílico. Alguns são formados de açúcares durante os estágios iniciais da reação escura da fotossíntese. Mas, em muitos casos, os precursores imediatos dos ácidos orgânicos são outros ácidos orgânicos ou açúcares (Kays, 1991).

É evidente que tanto o teor de açúcares como o de ácidos orgânicos foram equilibrados pelo número de frutos por planta.

Observando os dados econômicos (Tabela 4), verifica-se que o custo total médio diminui com o aumento da produtividade, apesar de as maiores produtividades serem observadas em plantios mais adensados (3.330 e"1.110 plantas/ha), estes apresentaram os maiores custos totais.

No sistema de comercialização exclusivamente para a indústria com receita média (Rme) ou preço de venda de $\mathrm{R} \$ 0,40 / \mathrm{kg}$, observa-se que $\mathrm{Rme}<\mathrm{CTMe}$, indicando que em todos os tratamentos a situação é de resíduo, especificamente resíduo negativo ( $\mathrm{Rme}<\mathrm{CopTMe}$ ).

Observa-se também que não há cobertura dos custos de curto prazo ou o chamado capital de giro ( $\mathrm{Rme}<\mathrm{CopVMe}$ ). Assim, ao persistir tal situação, há a necessidade de subsidiar os recursos variáveis ou a própria saída da atividade, diminuindo os prejuízos.

Analisando a situação de comercialização da fruta de forma mista (50\% para indústria e 50\% para consumo in natura- $\mathrm{R} \$ 0,55 / \mathrm{kg})$, apenas a densidade de 3.330 plantas/ha proporcionou resíduo $(\mathrm{Rme}<\mathrm{CTMe}$, especificamente resíduo positivo $(\mathrm{CTMe}<\mathrm{Rme}>\mathrm{CopTMe})$, cobrindo todos os custos variáveis e parte dos custos fixos. Para as demais densidades de plantio, a situação de lucro supernormal existe (Rme $>\mathrm{CTMe}$ ), indicando que, para qualquer outra densidade de plantas, o cultivo de maracujá na região de São Tiago a médio e longo prazos é de expansão, com a entrada de novos produtores, tornando a atividade mais competitiva.

Na comercialização para indústria, a receita líquida variou de (-)R $\$ 4.247,47 /$ ha no tratamento T1 a (-)R $\$ 1.763,14 /$ ha no tratamento T3 (Tabela 4). Considerando o sistema de comercialização "mista", a receita líquida variou de (-)R $\$ 274,27 /$ ha no tratamento $\mathrm{T} 1 \mathrm{a}(+) \mathrm{R} \$ 2.637,56 / \mathrm{ha}$ no tratamento T3. Neste caso, a maior eficiência técnica (produtividade em T6) não coincidiu com a maior eficiência econômica, por causa dos maiores custos do plantio adensado. Portanto, verifica-se que, neste momento, a rentabilidade econômica desta cultura depende muito do preço do maracujá, principalmente em anos em que a produtividade é baixa, causada ora por veranicos antecedendo a emissão floral ora por excesso de precipitação pluviométrica durante o florescimento.

Nesse contexto, em São Tiago e região, o preço do fruto para a indústria, nos anos de 2002, 2003 e 2004, foi de, aproximadamente, US $\$ 0,133 / \mathrm{kg}$ (câmbio de US $\$ 1,00: \mathrm{R} \$ 3,00$ ), portanto, abaixo do limite inferior do preço histórico de maior freqüência US $\$ 0,18 / \mathrm{kg}$ a US $\$ 0,25 /$ $\mathrm{kg}$ (Guedes \& Vilela, 1999) e próximo ao limite inferior do preço histórico real, pago pelas indústrias de suco, de US\$0,10/kg a US\$0,40/kg (Pires \& São José, 1994).

TABELA 4 - Custos econômicos, receita líquida da produção do maracujá, em diferentes densidades de plantio, provenientes das três safras acumuladas do maracujazeiro-amarelo. UFLA, Lavras-MG, 2004.

\begin{tabular}{|c|c|c|c|c|c|c|c|c|c|}
\hline $\begin{array}{c}\text { Tratamentos } \\
\text { Espaçamento }(\mathrm{m})\end{array}$ & $\begin{array}{c}\text { CFMe } \\
(\mathrm{R} \$)\end{array}$ & $\begin{array}{l}\text { CVMe } \\
(\mathrm{R} \$)\end{array}$ & $\begin{array}{l}\text { CTMe } \\
(\mathrm{R} \$)\end{array}$ & $\begin{array}{c}\text { CopFMe } \\
(\mathrm{R} \$ / \mathrm{kg})\end{array}$ & $\begin{array}{c}\text { CopVMe } \\
(\mathrm{R} \$ / \mathrm{kg})\end{array}$ & $\begin{array}{c}\text { CopTMe } \\
(\mathrm{R} \$ / \mathrm{kg})\end{array}$ & $\begin{array}{c}\mathrm{CT} \\
(\mathrm{R} \$ / \mathrm{ha})\end{array}$ & $\begin{array}{l}\text { RL (Indust.) } \\
\text { (R\$/ha) }\end{array}$ & $\begin{array}{l}\text { RL (Misto) } \\
\text { (R\$/ha) }\end{array}$ \\
\hline $\mathrm{T} 1=3,0 \times 1,0$ & 0,019 & 0,541 & 0,560 & 0,017 & 0,483 & 0,500 & $14.842,67$ & $-4.247,47$ & $-274,27$ \\
\hline $\mathrm{T} 2=3,0 \times 2,0$ & 0,020 & 0,512 & 0,531 & 0,018 & 0,457 & 0,475 & $13.918,62$ & $-3.443,42$ & 484,78 \\
\hline $\mathrm{T} 3=3,0 \times 3,0$ & 0,018 & 0,443 & 0,460 & 0,016 & 0,395 & 0,411 & $13.498,34$ & $-1.763,14$ & $2.637,56$ \\
\hline $\mathrm{T} 4=3,0 \times 4,0$ & 0,020 & 0,500 & 0,520 & 0,018 & 0,447 & 0,465 & $13.333,14$ & $-3.086,34$ & 756,21 \\
\hline $\mathrm{T} 5=3,0 \times 1,0$ com desbaste & 0,018 & 0,495 & 0,513 & 0,016 & 0,442 & 0,458 & $14.853,87$ & $-3.262,27$ & $1.084,58$ \\
\hline $\mathrm{T} 6=3,0 \times 1,5$ com desbaste & 0,017 & 0,453 & 0,470 & 0,015 & 0,405 & 0,420 & $14.264,54$ & $-2.127,34$ & $2.424,11$ \\
\hline $\mathrm{T} 7=3,0 \times 2,0$ com desbaste & 0,019 & 0,505 & 0,525 & 0,017 & 0,451 & 0,468 & $13.876,31$ & $-3.297,11$ & 670,09 \\
\hline Média & 0,019 & 0,493 & 0,511 & 0,017 & 0,440 & 0,457 & $14.083,93$ & - & - \\
\hline
\end{tabular}

* CFMe - custo fixo médio; CVMe - custo variável médio; CTMe - custo total médio; CopFMe - custo operacional fixo médio; CopVMe - custo operacional variável médio; CopTMe - custo operacional total médio; $\mathrm{CT}$ - custo total; $\mathrm{RL}$ - receita líquida.

*Considerou-se a receita líquida (RL) para dois sistemas de comercialização: venda exclusiva para indústria, com receita média (Rme) de $\mathrm{R} \$ 0,40 / \mathrm{kg}(\mathrm{preço} \mathrm{da} \mathrm{fruta),}$ durante o período de estudo e o sistema Misto $(\mathrm{R} \$ 0,55 / \mathrm{kg})$, o qual, além da opção de comercialização para a indústria, o produtor pode também comercializar o fruto no mercado de fruta fresca, com preço de $\mathrm{R} \$ 0,70 / \mathrm{kg}$ (preço pago ao produtor na CEASA-MG). 


\section{CONCLUSÕES}

Com base nos resultados obtidos, conclui-se que a densidade de plantio, variando próximo a 1.110 plantas por hectare $(3,0 \mathrm{~m}$ x 3,0 m), demonstra ser mais produtiva e mais lucrativa que nos espaçamentos atualmente recomendados ( $3,0 \mathrm{~m}$ x 5,0 m) e em plantios adensados ( 3.330 plantas/ha). Plantio adensado (2.220 plantas/ha) com desbaste na segunda safra (1.110 plantas/ha) apresenta boa produtividade, porém tem aumento no custo de produção. O tamanho do fruto e os teores suco, sólidos solúveis totais e acidez titulável não foram afetados pela densidade de plantio.

\section{AGRADECIMENTOS}

Ao Sr. Juarez Amaral Viana de Assis, proprietário da fazenda Sant'Ana, por ter financiado o projeto. À CAPES e ao CNPq, pela concessão de bolsa de estudo aos autores.

\section{REFERÊNCIAS}

ANDRADE, J. M. de B.; BRANDÃO FILHO, J. E. T.; VASCONCELOS M. A. da S. Efeito da densidade de plantio no primeiro ano de produção do maracujazeiro-amarelo, no noroeste do Paraná. Revista Brasileira de Fruticultura, Cruz das Almas, v.16, n.2, p.49-54, set. 1994.

ARJONA, H. E.; MATTA, F. B.; GARNER Jr., J. O. Temperature ans storage time affect quality of yellow passion fruit. HortScience, Alexandrina, v.27, n.7, p.809-810, 1992.

ASSOCIATION OF OFFICIAL ANALITCAL CHEMISTS. Official methods of analysis of the Association of official Analitical Chemists. $15^{\text {th }}$ ed. Washington, $1990.2 \mathrm{v}$.

BRASIL. Ministério da Integração Nacional. Produção frutícula nacional. Brasília, 2005. Disponível em: $<w w w . i n t e g r a c a o . g o v . b r>$. Acesso em:25 fev. 2005.

CEREDA, E.; VASCONCELOS, M. A. da S. Influência da densidade de plantio na produtividade do maracujazeiro-amarelo (Passiflora edulis Sims. f. flavicarpa Deg.). Revista Brasileira de Fruticultura, Cruz das Almas, v.13, n.1, p.131-135, out. 1991.

FORSHEY, C. G.; ELFVING, D. C. Fruit numbers, fruit size, and yield relationships in 'McIntosh' apples. Journal of the America Society Horticultural Science, Alexandria, v.102, n.4, p.399-402, 1977.

GAMARRA ROJAS, G.; MEDINA, V. M. Variações físico-químicas do maracujá-amarelo em relação à pigmentação da planta. Revista Brasileira de Fruticultura, Cruz das Almas, v.17, n.3, p.103-110, dez. 1995.

GUEDES, L. de O.; VILELA, P.S. O mercado do maracujá. Belo Horizonte,FAEMIG/Infoagro, $1999.16 \mathrm{p}$.

KAYS, J. S. Postharvest physiology of perishables plant products. New York: Avi, 1991.543 p.

KITS, H.; FELDENS, A. M.; MANICA, I.; FIORAVANÇO, J. C. Análise econômica de densidade de plantio do maracujá-amarelo no município de Porto Lucena-RS. Pesquisa Agropecuária Brasileira, Brasília, v.31, n.7, p.497-502, jul. 1996.

LIMA, A. deA.; CALDAS, R. C.; BORGES, A. L.; RITZINGER, C. H. S. P; TRINDADE, A. V.; PIRES, M. de M.; MIDLEJ, M. M. B. C.; MATA, H. T. da C.; SOUZA, J. da S. Cultivo intercalado e controle de plantas daninhas em plantios de maracujá-amarelo. Revista Brasileira de Fruticultura, Jaboticabal, v. 24, n. 3, p. 711-713, dez. 2002.
MANICA, I.; FIORAVANCO, J. C.; BARRADAS, C. I. N.; KITS, H. Seis espaçamentos de plantio e produção do maracujazeiro-amarelo (Passiflora edulis f. flavicarpa Deg.) em Porto Lucena, RS. Pesquisa Agropecuária Brasileira, Brasília, v. 29, n. 7, p. 1083-1090, jul. 1994a.

MANICA, I.; RITZINGER, R.; MARONDIN, G. A. B. Seis espaçamentos e três anos de produção do maracujazeiro-amarelo (Passiflora edulis f. flavicarpa) em Guaíba-RS. In: CONGRESSO BRASILEIRO DE FRUTICULTURA, 8., 1994, Salvador. Anais... Salvador: Sociedade Brasileira de Fruticultura, 1994b. p. 810-811.

MANICA, I.; RITZINGER, R.; MUNDSTOCK, E. C.; MARODIN, G. A. B.; KOLLER, O. C. Efeito de seis espaçamentos de plantio no $2^{\circ}$ ano de produção do maracujá-amarelo (Passiflora edulis f. flavicarpa Deg.) em Guaíba/RS. Revista Brasileira de Fruticultura, Cruz das Almas, v.11, n.1, p.25-30, abr. 1989.

NASCIMENTO, W. M. O.; TOMÉ, A. T.; OLIVEIRA, M. do S. P. de; MULLER, C. H.; CARVALHO, J. E. V. de. Seleção de progênies de maracujazeiro-amarelo (Pasiflora edulis $f$. flavicarpa) quanto à qualidade de frutos. Revista Brasileira de Fruticultura, JaboticabalSP, v.25, n.1, p.186-188, abril 2003

PACE, C. A. M.; ARAÚJO, C. M. Efeito de densidade de plantio na cultura do maracujá-amarelo (Passiflora eduli f. flavicarpa Deg.). In: CONGRESSOBRASILEIRODEFRUTICULTURA, 6, 1981, Recife. Anais... Recife: Sociedade Brasileira de Fruticultura, 1981. p.972982.

PIRIS, M. de M.; SÃO JOSÉ, A. R. Custo de produção e rentabilidade da cultura do maracujazeiro. In: SÃO JOSÉ. A. R. (Ed.). Maracujá: produção e mercado. Vitória da Conquista: UESB, 1994. p. 223-233.

QUAGGIO, J.A.; PIZA JÚNIOR, C.T. Nutrição e adubação da cultura do maracujá. In: RUGGIERO, C. (Ed.). Maracujá: do plantio à colheita. Jaboticabal: Funep, 1998. p.130-156.

REIS, R. P. Fundamentos de economia aplicada. Lavras: UFLA/FAEPE, 2002.95p

RITZINGER, R.; MANICA, I.; RIBOLDI, J. Efeito do espaçamento de plantio sobre a produção do maracujá-amarelo em Viamão-RS. Pesquisa Agropecuária Brasileira, Brasília, v.22, n.8, p.809-815, ago. 1987.

RITZINGER, R.; MANICA, I.; RIBOLDI, J. Efeito do espaçamento de plantio sobre a produção do maracujá-amarelo em Viamão-RS. Pesquisa Agropecuária Brasileira, Brasília, v. 22, n. 8, p. 809-815, ago. 1987

RUGGIERO, C.; SÃO JOSÉ, A.R.; VOLPE, C.A.; OLIVEIRA, J.C. de; DURIGAN，J.F.; BAUMGARTNER,J.G.; SILVA， J.R. NAKAMURA,K.; FERREIRA, M.E.; KAVATI, R.; PEREIRA, V. de P. Maracujá para exportação: aspectos técnicos da produção. Brasília: EMBRAPA-SPI, 1996. 64p. (Publicações Técnicas FRUPEX, 19).

SACRAMENTO, C. K. do; PINTO, L. R. M. Efeito do espaçamento do maracujazeiro-amarelo no sudoeste da Bahia. In: CONGRESSO BRASILEIRO DE FRUTICULTURA, 10., 1989, Fortaleza. Anais... Fortaleza: SBF, 1989. p. 370-374.

SÃO JOSÉ, A. R. A cultura do maracujá nas Regiões Norte e Nordeste do Brasil. In: SIMPÓSIO BRASILEIRO SOBRE A CULTURA DO MARACUJAZEIRO, 5, 1998, Jaboticabal. Anais... Jaboticabal: FUNEP, 1998. p.3-17.

SILVA, J. R.; OLIVEIRA, H.J. de O. Implantação da cultura, manejo e tratos culturais. In: BRUCKNER, C. H.; PICANÇO, M. C. Maracujá: tecnologia de produção, pós-colheita, agroindústria, mercado. Porto Alegre: Cinco Continentes, 2001 